\title{
An Assessment of Industry Position on Shared Equity Housing Model development in the UK
}

\begin{abstract}
This paper investigated affordable housing problems and how they impact the development of Shared Equity Housing Models (SEHM) with emphasis on the Community Land Trust (CLT). The methodological approach identified and tackled inherent industry sources of barriers to Community Land Trust Shared Equity Housing Models (CLT SEHM) development through literature reviews and the text analysis of semi-structured interview responses from key stakeholders. Findings indicated that industry sources of barriers to CLT development occur within crucial bilateral dimensions impacting its capabilities as an adoptable model for major housing providers, and for local practitioners in well-defined communes for localised housing. This study opens a further debate on the downsides of the current housing delivery arrangement, and the need for an improved capacity for innovation through more sustainable alternatives/policies - particularly in a sector dominated by tested mainstream options, however with performance and affordability inconsistencies - in UK housing development.
\end{abstract}

Keywords: housing; affordable housing; industry; shared equity housing models; SEHM; community land trust; CLT. 


\section{Introduction}

According to Best (2003) policy plays a major role in the state of housing irrespective of community or country. He was of the view that; housing policies can make an immense difference to tackling disadvantages, and also ensures that households even on the lowest incomes live in decent homes and engaging communities. In contrast, if policy fails, this could result in the lack of satisfactory homes, and a reduced quality of life. Despite continual government effort, research still reflects a shortfall in homes in the United Kingdom (UK). The level of home ownership was predicted to fall drastically, according to a National Housing Federation (2011) forecast which indicated an expected slump of about $63.8 \%$ over the next decade. This figure represents the lowest level since the mid-1980s. The forecast further suggests that huge deposits, inflationary house prices and strenuous lending conditions could be responsible for this phenomenon. This supports the long existing trend that the supply of homes has failed to keep pace with demand, hence creating a lingering housing deficit and a steady decline in supply over the years.

Policy however remains a complicated tool in housing development; as often noble its targets and intentions might seem, they sometime fall short of intended goals. Therefore, shutting out budding solutions in a sector where multiplex networks of players, models, frameworks interact, clash, and preferably evolve unpredictably. To refine these networks, overall efforts aimed at improving housing efficiency towards individuals and households at the lowest rung of the housing ladder remains a tall order, even for the most technologically advanced countries. Moreover, it appears that research strategies are not being developed in a way that ensures players within these networks evolve positively through policies that take into consideration concerns that cut across key ideological and innovative divides. Usually, key stakeholders are expected to respond to indicators which are either positive or negative economic realities. However, it appears that interventions are not always inclusive. Moreover, they are seemingly based largely on inadequate data, impulse and political drivers, which sometimes also falls short of intended targets.

In the UK, it appears research on the housing development sector is not addressed holistically (Kenny, 1992). The scope of mapped data is usually restricted to conventional housing key indicators, structural parameters prioritised by policy makers and governmental institutions. This on the long run might be omitting data surrounding other alternative housing/property networks and structures, thereby relegating their existence to the fringes of restricted portals, i.e. outside the conduit that drives dominant mainstream policies. Moreover, in situations where they are included, the debate is sometimes misrepresented, lacking in-depth grasp of how mainstream options could be hampering these alternatives with the potential to improve the state affordable housing delivery. Perhaps, these trends could be symptoms of deep rooted problems with policy and approach to housing alternatives. In order to shed more light on these issues, this research focused on the Community Land Trust Shared Equity Housing Model (CLT SEHM), which literature has consistently touted as a viable alternative to traditional options. Shedding light on these possibilities involved the examination of connections between concerned players in the affordable housing sector and the prevailing shortfalls in housing 
supply. Furthermore, how these connections, if established affect or hamper the development and acceptability of the CLT SEHM in mainstream housing provision were also explored. The investigation process involved key literature reviews, perception mapping of concerned stakeholders; including experts in both affordable housing and alternative delivery platforms. Furthermore, in order to mitigate traditional housing data deficiencies, particularly when non mainstream housing models are concerned, a modified housing model pathway methodology based on constructionism was employed. This was done in an attempt to derive meaning within organisation behaviour and implications for relevant stakeholders including housing delivery model beneficiaries.

\section{Literature Review: A study of the nexus between affordable housing problems and sources of barrier to CLT SEHM}

In regards to UK housing shortfalls and what appears to be partial failure of policy, competing schools of thought disagree on solutions. Moving forward, there appears to be consensus on causation, with research findings consistently suggesting that huge deposits, inflationary house prices and strenuous lending conditions are at least in part responsible for the housing deficit phenomenon. However, on the issue of the under researched alternative delivery models, investigating culpability and impact on stakeholders remains a contentious issue. This is further buttressed by studies confirming inefficient qualitative and explicit depth in regards to the framework guiding commissioned studies by government departments (Clapham, 2010). The potential impact of some of these shortcomings on alternative housing delivery models is the development of policies less focused on innovative solutions and heavily reliant on conventional structures and networks (Housing Corporation, 2007; Carnis, 2009). Therefore, most of the potentials inherent in alternatives solutions might end up not maximised.

To this end, how researchers respond to the challenge of ensuring that alternative models are not lost within these convoluted networks is of paramount importance. Similarly, the structural viability and possible limitations of these alternatives are also contentious subjects. Perhaps, these models are victims of their own networks, and their underperformance could be linked to competition and the over reliance on traditional delivery platforms. Additionally, these structures and operations could serve as potential or active barriers impacting other options and the overall affordable housing sector. This could shed more light on not only affordability and supply, but also the urgent need for strategic reforms. In achieving these targets, an effective research approach ought to be adopted that addresses lapses in standard empiricist methodologies used in policy development, which appears to be contributing very little to the housing discourse in general (Kenny, 1992). Also, for the seemingly under researched alternative housing delivery models, such as the CLT SEHM, this conventionally favoured methodologies appear to be doing little to advance new knowledge outside the confines of mainstream built environment discourse.

Statutorily, according to Community and Local Governments (2008) the CLT is a local community-controlled organisation set up to own; manage land and other assets in perpetuity for the benefit of the community. These assets could include affordable housing, workspaces, agricultural facilities, commercial outlets, or community facilities. The SEHM structure is 
typically designed to ensure that the CLT provides permanently affordable housing within the industry's statutory confines. This involves the adoption of a form of rental and shared equity ownership model that enables beneficiaries to build up just enough equity for a future part purchase, but not to the extent that it hampers the benefits of future tenants/owners. Hence, a significant portion of the equity growth remains with the CLT, therefore keeping the houses affordable in perpetuity (Paterson and Dunn, 2009). As tenable as this structure might appear, in regards to viable affordable housing development, the CLT alongside other trusts and cooperative systems are largely underrepresented in the UK's housing stock (Birchall, 2004; Clark, 2012).

There are indications that key players involved primarily with affordable housing supply problems are somewhat linked with the lack lustre plight of the CLT SEHM. The HCA (Homes and Community Agency) pre-qualification processes (PQP) and Housing Quality Indicators (HQI) for example are suggested to be inappropriate for new, small organisations it aims to regulate (CLG, 2011), and might contribute to difficulties faced in accessing grants. For the CLT SEHM, investors appear to show preference for HA (Housing Association) models because it is low risk and mostly government backed (Lambert, 2011). Rethinking the ramifications surrounding investor choices, existing research examining the effect of competition on non-profit enterprise, found that competition becomes unfair to service providers that are not entirely motivated to make profits. They are mostly muscled out by their limited ability to advertise and manage knowledge as well as competing profit-seeking agencies in value driven markets (Deakin, 1994).

Furthermore, how dominant actors react is quite instructive on the relevance of crushing rivals by capitalising on policy changes, which might have intended/unintended consequences on useful/innovative options at relative infancy. This is an absolutely viable and strategic response within rational competitive business/industry environments, much more for the increasingly deregulated and highly privatised neo classical economic housing market structures. These consequences could manifest as changes in micro housing policy/regulatory environments (Rajagopal, 2015), which could lead to either viable benefits or detrimental effects depending on which side of the ontological dualism the housing delivery model falls. In the case of the CLT SEHM, it appears to be on the detrimental end, with its success almost entirely subjective to policy interplays as dictated by institutional top down influences/models - despite their underperformance - on the SEHM and its development network as a whole (Fig 1). 


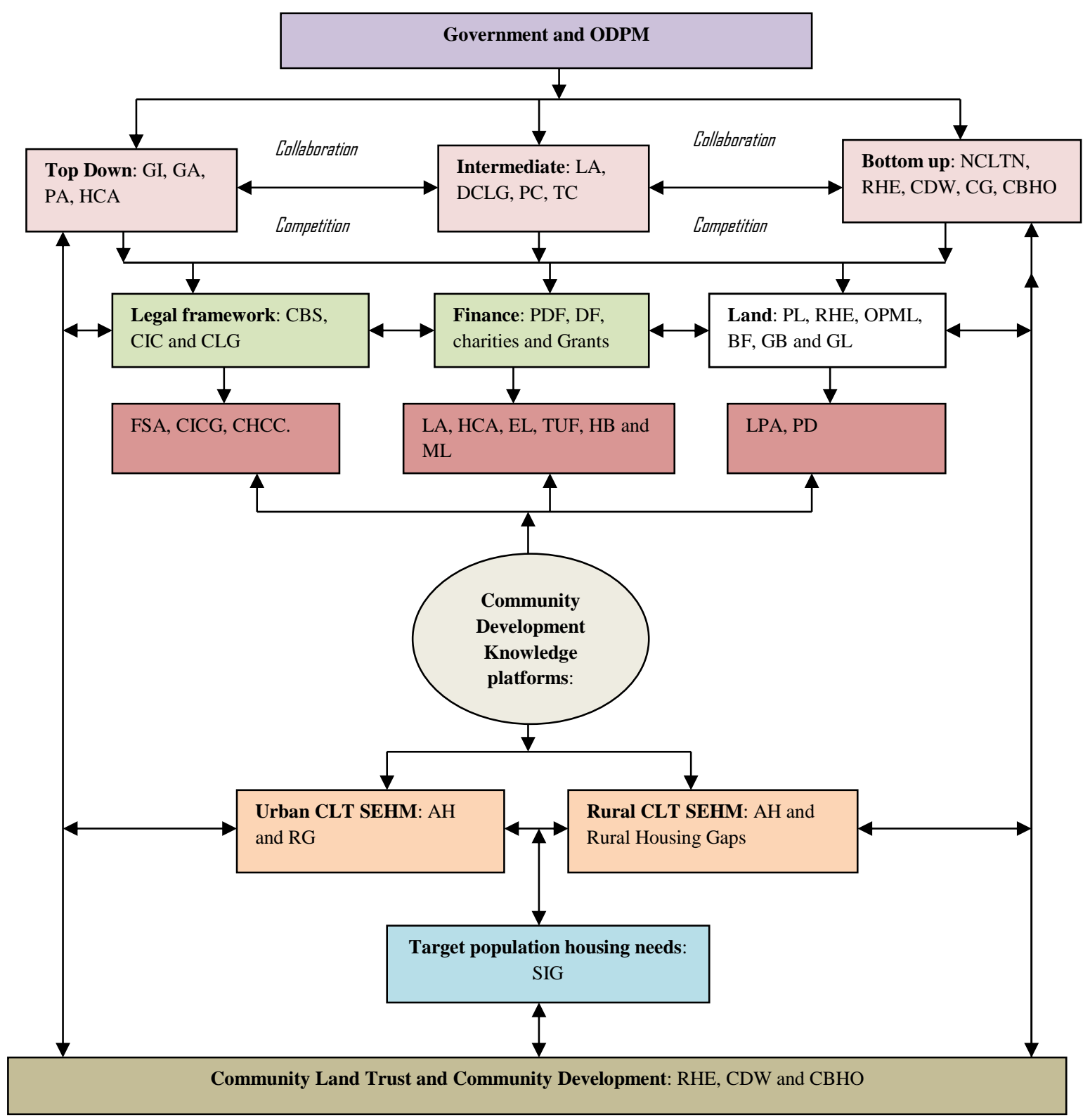

KEY

AH-Affordable Housing
BF-Brown field land
CBS-Community Benefit Society
CIC-Community Interest Company
CLG-Community Limited by
Guarantee
CHCC-Company House and
Charity Commission
CICR-Community Interest
Company regulator
CBHO-Community Based Housing
Organisation
CDW-Community Development
Worker

CG-Community Groups DCLG-Department of Community Local Government DF-Development Fund EL-Ethical Lenders FSA- Financial Service Authority GI-Government Institutions GA-Government Agencies GB-Green belt GL-Green Land HB-High street banks PL: Public Land
HCA-Homes Community Agency

LA-Local Authorities

LPA-Local Planning Authorities ML-Mortgage lenders NCLTN-National Community Land Trust Network RG-Regeneration Goals PD-Private Developers PDF-Public Development Fund RHE-Rural Housing Enablers SIG-Special Interest Groups (FTB, Minority Ethnic Groups, Low income earners). TUF-Top up fund

Fig 1: The CLT SEHM Stakeholder Network (Study's illustration, 2018). 
As literature sheds light on what seems to be industry favoured 'top down' delivery model's inability to adequately meet up with housing aspirations and empowerment of target communities (Bretherton \& Pleace, 2008). Regardless, in the UK the CLT SEHM appears to be under constant threat from sector policies such as stair casing demands and the right to leaseholder enfranchisement (this is a platform that gives legal rights to residents to acquire the free-hold of the land in addition to the housing). These imposed limitations are antithetical to the CLT SEHM structure, due to negative impacts it might have on its ability to ultimately keep the housing affordable in perpetuity. The aforementioned potential barriers lends to a bureaucratic dependent structure that might be imposing a 'top down' hold on the potentials of the CLT SEHM (Housing Corporation, 2007; Carnis, 2009), buttressing the existence of an ontological dualism rarely considered in built environment research.

Reconciling these outlooks in the UK housing context, recent studies suggest the limited existence of positive cooperation within local authority/developers' networks adopting the CLT SEHM in which beneficial relationships have been formed to achieve housing goals. However, there are exceptions as exemplified by the case of Chipping and Cornwall CLT with clear evidence of partnership in delivering housing goals (National CLT Network, 2017). Moreover, the present situation might not augur well with the Smyth (2007) position on the need for fair engagements and level playing fields among stakeholders. As the CLT SEHM structure is still relatively dependent on the HCA favoured HAs, further impacts of its prescriptions on alternative housing development strategies are demonstrated with the experience of Stocksfield Community Association Trading Arm (SCATA). Despite achieving modest successes with 4 flats and 3 bungalows, the association also garnered support from the County Council and the HCA Affordable Homes programme. However, they could not proceed until the fulfilment of a crucial HCA Pre-Qualification Process (PQP), which required receiving support from a selected HA. The Housing Quality Indicators (HQI) requirements are also considered inappropriate for new, small developers and SEHM organisations it aims to regulate (CLG, 2011). Moreover, developments like the North Dorset, Threshold Centre (Synergy Housing) scheme which incorporated additional features that address environmental sustainability concerns like bio-mass heating system, a bio-digester, solar photovoltaic and a recycling system for water and waste (UK Cohousing Network, 2017) also faced restrictions from imposed stringent regulations. Considering the relative small scope of the project (7 owner occupied cottages, 2 shared ownership and 5 affordable rented flats) and collaboration with a large HA, the desire to scale up the development to accommodate demand has not been encouraging.

This section explored the existence of links between affordable housing problems and the CLT dilemma; they however lack depth on how and why these links exist. They also appear to be deeply entrenched in policies and political weaknesses. Hence, there is the need for more vigour in identifying industry related sources of barriers causing the underrepresentation of the CLT SEHM. Moreover, how they can be tackled practically from the perspective of concerned stakeholders was also addressed subsequently. 


\section{Research Methodology}

For this study's methodology, the downsides of traditional research approach to housing, social complexities, attitudinal assessments of actors and barriers cannot be unravelled without addressing the hierarchical dimension within alternative housing development networks in a post-modern domain. Therefore, investigating/addressing/responding to policy fallouts (see Rajagopal), and CLT SEHM experience in the UK will require a more nuanced approach. According to Clapham (2010) it should involve an investigation of the directional interplay between organisational policies and tenets. This fundamentally exists in a state of dualism, where a dominant approach appears to stifle/curtail alternatives in a competitive environment. This interplay relies on a support mechanism aided by 'top down' institutional policies seemingly pitted against a 'bottom up' based system of players and policy beneficiaries.

From a social constructionist standpoint, assessment should be guided by the development of jointly constructed understanding of the phenomenon that forms the basis for shared assumptions about reality and how it is experienced (Leeds, 2009). This approach undiluted is however inefficient when dealing with implicit structural dimensions like the investigation of the 'top down' and 'bottom up' influence within housing development networks and how they interact. These structures are the rules inherent in stakeholder experiences as memory traces to execute social actions/reactions based on what they know about what they do, and why they do it (Giddens, 1984). However, it remains ambiguous how to explicitly determine which structure's reality is or should be dominant, perhaps seen as acceptable in a social construct. In line with Searle (1995), these reactions/realities are not explicitly personal opinions, but the extreme, modal formulations that actual persons, individuals can then observe. This might however imply taking a middle position away from the extremes irrespective of the dominant discourse. In search of this middle ground that effectively achieves validated results, unravelling hidden meanings from conflicting discourse becomes the focus. From Sarre (2007), a housing pathway framework was developed, which according to Clapham (2010), guides the application of the concept of structuration beyond an empirical approach.

\subsection{SEHM 'Top Down and Bottom-Up' housing pathway research approach}

Methodologically, adopting a robust literature review, the semi-structured interview and a stringent analytical process helped achieve the housing pathway elements elucidated by Clapham (2010). This focused on the identification of the bounds of knowledgeability to discover the unacknowledged or unconscious meanings held by individuals and the unintended consequences of actions. To this end, achieve the end goal of specifying structural orders/factors which impinge on actions and the study focus. The in-depth nature of the interviews is necessary to capture the respondents' perceptions in their own words, allowing the interviewer to present the meaningfulness of the opinions and experiences from the respondent's own perspective (Rubin and Rubin, 2005). This involved the use of investigative tools to assess stakeholders' perspectives on policy approach to affordable housing in the UK and its impact on SEHM from a 'bottom up' and 'top down' perspective. Therefore, developing a clear understanding of objectives in order to define the range of stakeholder/respondent participation and the extraction of valid outcomes deemed crucial, as suggested by Vallejo, 
Nancy, \& Pierre (2004). Also, the semi-structured format helped the interviewer pace the interview. Thus, ensuring a systematic and comprehensive approach to the research process expected to capture reality in a time frame (Seale, 2004). To this effect, the interview process focused on themes developed from literature (reviewed historically till date), targeted at stakeholders involved in affordable housing, CLT SEHM, community ownership and management related organisations, which covers both sides of the dualism.

Data generated (as responses) on these issues were recorded, transcribed and reviewed. Nvivo software was utilised to help organise the recordings through text analytical methods. This helped increase transparency and robustness of the research outcomes generated directly from the raw context of the coded materials. Moreover, the employment of illustrative quotes helped limit research bias (Miles \& Huberman, 1994). Furthermore, deductions from generated codes and patterns from establish major themes were analysed to arrive at a consensus on meanings. Additionally, this process aided identification of the bounds of knowledgeability, the investigation of barriers and drivers to SEHM growth. Moreover, the unacknowledged or unconscious meanings held by individuals on both sides of the dualism were also unravelled and documented. Therefore, the unintended consequences of actions could be mapped effectively. For this stage of the research, the interviews and analytical process alone helped achieve data saturation sufficient to effectively conclude the housing pathway commensurate with specifying structural orders/factors which impinge on actions and the study focus.

Due to low level of mutual housing knowledge among both housing experts and laymen alike (CCMH, 2009), the study's enquiry process employed key informants for its semi structured interviews. This is a technique that utilises rich research specific information sources, and due to the limited number of key informants, seven representatives for each organisation were initially deemed suitable. However, as new themes stopped emerging, thematic and theoretical saturation was reached at an average of three interviews for each of the organisations. The stringent selection criteria, alongside an enquiry framework that focused on a rigorous interpretation of stakeholder policies and its actual impact on CLT SEHM greatly accelerated thematic saturation. The participant/informants' selection criteria included a robust practical experience database that has been garnered from actual active field presence involving day to day meetings and dealing with local CLT advocates and enthusiasts. Moreover, an in depth involvement in CLT SEHM development from implementation stages to completion in an operational capacity that cut across well over 10 local authorities, and even more for organisation representatives with national representations were also a key criteria.

\subsection{Organisation Categorisation}

The organisations were classified strategically according to their mode of operation in affordable housing and community initiatives, i.e. the top-down and the bottom-up classification informed by the concepts of the 'weak and strong' dualism existing in opposing philosophical contexts. This represented the relationship between the housing industry's 'top down' agents/stakeholders reaction to competition and the impact on 'bottom up' based SEHM practitioners, which according to Bland (2008) could limit community asset ownership and 
involvement that the CLT SEHM structure thrives on. Due to the anonymous treatment of interview respondents, the top down organisation respondents were identified with representative descriptors of: (TD1, TD2, TD3, TD4.., TD7) and (BU1, BU2, BU3 ..., BU7) which represented the respondents that fulfilled key informant selection criteria earlier mentioned. The top down categorisation represents mostly agencies and institutions that typically derive their funding from the government to implement their affordable housing agenda for example (HCA and its subsidiaries) (Table 1), while the bottom-up categorisation are organisations whose activities are centred on community ownership, voluntary and management initiatives when it comes to housing delivery and the growth of the CLT SEHM, i.e. NCLTN (National Community Land Trust Network) and CDW (Community Development Workers), and CLT SEHM developments (Table 2).

\begin{tabular}{|c|c|c|c|c|c|}
\hline Code & Background & $\begin{array}{l}\text { Housing } \\
\text { Experience }\end{array}$ & $\begin{array}{l}\text { CLT } \\
\text { Experience }\end{array}$ & SEHM & Representation \\
\hline TD1 & Housing Development & $>10 \mathrm{yrs}$ & $3-5 y r s$ & & Government Agency \\
\hline TD2 & Housing Development & $>10 \mathrm{yrs}$ & $6-10 \mathrm{yrs}$ & & Government Agency \\
\hline TD3 & Project Management & $6-10 \mathrm{yrs}$ & $1-2 \mathrm{yrs}$ & & Housing Association \\
\hline TD4 & $\begin{array}{ll}\text { Planning } & \text { and } \\
\text { Regeneration } & \\
\end{array}$ & $>10 \mathrm{yrs}$ & 6-10yrs & & Planning Authority \\
\hline TD5 & Facilities Management & $6-10 \mathrm{yrs}$ & $3-5 y r s$ & & Housing Association \\
\hline TD6 & Management & $3-5 y r s$ & $<1 \mathrm{yr}$ & & Local Authority \\
\hline TD7 & Council Housing & $1-2 y r s$ & $3-5 y r s$ & & Local Authority \\
\hline
\end{tabular}

Table 1: Top down Respondent Profiles

\begin{tabular}{lllll} 
Code & Background & Housing Experience & CLT SEHM Experience & Representation \\
\hline BU1 & Affordable Housing & $>10$ & $>10$ & NCLTN \\
\hline BU2 & Community Development/Finance & $>10$ & $>10 \mathrm{yrs}$ & CFS \\
\hline BU3 & Asset Management & $>10$ & $>10 \mathrm{yrs}$ & CLT SEHM \\
\hline BU4 & Community Consultancy & $6-10 \mathrm{yrs}$ & $6-10 \mathrm{yrs}$ & NCLTN \\
\hline BU5 & Social Enterprise & $6-10 \mathrm{yrs}$ & $>10 \mathrm{yrs}$ & CLT SEHM \\
\hline BU6 & Community Development & $>10 \mathrm{yrs}$ & $>10 \mathrm{yrs}$ & RHE \\
\hline BU7 & Community Organisation & $3-5 \mathrm{yrs}$ & $3-5 \mathrm{yrs}$ & CLT SEHM
\end{tabular}

Table 2: Bottom up Respondent Profiles

\subsection{Interview process, data collection and analysis}

The investigation process included phone and face to face tape recorded interview sessions. Stakeholder responses to sample open ended questions focused on the following three areas:

1. The ways qualifying and implementation processes impact affordable housing delivery and the enabling capacity of concerned stakeholders in regards to the CLT.

2. Assessment and implications of the overdependence of the UK housing sector on traditional affordable housing providers and models.

3. The state of collaboration opportunities and funding difficulties for aspiring or start up practitioners/developers adopting the CLT SEHM. 
The responses from both classifications were recorded, transcribed and reviewed. Nvivo 9.0 helped organise the transcribed recordings through its text analytical techniques that increased transparency and robustness of the research outcomes. Moreover, they were generated directly from the raw context of the coded materials employing illustrative quotes, hence limiting research's bias.

During data collection and analysis, thematic and theoretical saturation was reached at 14 interviews overall. The coding process involved:

- Assigning each data source to respective nodes according to research classification.

- Text Search Query function was ran to classify the issues and recurrent themes generated from respondents

- Nodes (representing a host of varying data, from key words, all in distinct sentences, quotations and references) where created for each theme according to respondent and classification ('top down or bottom up').

- A 'Matrix Coding Query' was run to identify the number of references made by each respondent on respective themes.

- Each theme was coded with its respective number of references and respondents.

- A Coding Comparison Query' was run to assess concurrent and conflicting patterns.

- Deductions where made from generated codes and patterns from establish major themes to arrive at a consensus on meanings (Miles \& Huberman, 1994), so conclusions can be made on research focus.

For example 'Qualification process difficulties' was a coded theme with its respective frequency of references, respondents and a sub-coded theme representing (Preference and the enabling capacity in the housing sector theme). The theme had had 6 sources and 8 references (Table 3). This implied that 6 respondents were actively referenced within the context of this theme and 8 significant references (answers or key points) were identified. These nodes were further analysed by building relationships and seeing how each attributes affects one another.

This exercise was very useful in organising the data captured in the interviews and the rich consolidation of the contextual nature of information received. This interpreted the interdependency of the explored questions and also assisted in collating individual perspectives. Reporting these themes involved assessing relevant topics and familiar contexts in the form of raw data reflecting how the participants shared them during the interview process. Furthermore, the extraction process involved the descriptive statements where the researcher summarised the participants' comments, hence providing illustrative examples using the raw data. Finally, the interpretation was built on the descriptive data, where the meanings were presented raw, rather than a simple summary. This process was carried out objectively without reflecting researcher bias. To this effect, the following were considered during the investigation:

- The participants' characteristics and the descriptive phrases and words used.

- The points of view held among respondents with common characteristics. 
- Description of the respondents' enthusiasm and the consistency between comments and their reported experiences remained vital for the investigation.

Moreover, a further validation of findings was conducted from 2016 - 2017 with 4 built environment academics active in sustainable construction and housing development policy research in the UK, with no significant thematic variation. Consequently, the thematic constructs remained fundamentally unchanged.

\section{Interview Findings}

\subsection{Preference and the enabling capacity for CLT SEHM}

This section analysed the responses to questions asked which centred on the ways qualifying and implementation processes impact affordable housing delivery. This helped to capture the enabling capacity of concerned stakeholders in regards to the CLT SEHM development.

\begin{tabular}{llll}
\multicolumn{2}{l}{ Themes/Subthemes } & Sources & References \\
\hline \multicolumn{2}{l}{ Preference and enabling capacity in the housing sector } & 14 & 22 \\
\hline 1 & 'Qualification' process 'difficulties' & 6 & 8 \\
\hline 2 & Affordable housing project 'bidding' ‘complications' & 4 & 8 \\
\hline 3 & Limitations in mainstream recognition for CLT strengths & 8 & 8
\end{tabular}

Table 3: Collation for 'the preference and enabling capacity in the housing sector' theme

In response to the link between affordable housing problems and the CLT SEHM, TD1 revealed that, not all the problems associated with affordable housing can be ruled as having a negative impact or linked with the CLT directly. Regardless, this does not rule out the possibility that they might be connected on the long run, should the CLT attain a more mainstream appeal. Furthermore, on the question of the impact of implementation policies on the CLT SEHM, the HCA pre-qualification process (PQP) as a barrier was in constant reoccurrence from BU2 and BU6 respondents respectively. On the contrary, TD1 did not view this wholly as a problem, suggesting the intentions of the processes are justifiable.

'The function of the PQP is to create necessary checks and balances to regulate affordable housing quality and control land assets; it was not intended to harm anyone apparently'

BU3 respondent however disagreed, with the view that the PQP adopted by the HCA might be just too rigorous or rather inappropriate for new, small CLT organisations and developers. Further suggestions include that, the process is presumably more beneficial to local authorities in retaining control of community development projects than it is to affordable housing provision, which should be its primary aim.

'[...] planning authorities could be unknowingly working against community housing development initiatives, due to the need to retain control of planning decisions' 
Moreover, BU2 believed that most of the projects that do sail through PQP standards are likely well-funded and centrally supported, therefore squeezes out competing alternatives. This confirms in practice the position of Stoker (2011) on potential implications of undefined fallouts of dependence rather collaboration.

Addressing the question of enabling capacity of stakeholders, respondents from all referenced 'top down' representatives viewed their roles to be that of enablers when it comes to CLT development. However, responses from BU2 suggest that problems are often encountered by CLTs trying to wade through imposed regulations ('top down' bureaucratic hurdles). Therefore the research focused roles of stakeholders are not pre-determined in regards to the CLT SEHM. This study however views the enabling role of traditional 'top down' institutions as relative depending on their level of involvement in the funding of a CLT SEHM development. A cited example was the case of the Holy Island of Lindisfarne community development trust (a civil parish in the North East of England), the first CLT to win a bid for HCA funding. BU3 highlighted:

'[...] as it is interdependent on the particular respective posture or interests they assume or have in regards to the concerned project at hand, as long as it does not go against their own agenda at that point in time [...] Lindesfarne happen to have fitted into this role, despite the really difficult hurdles it had to cross in fulfilling what is a never ending grant conditions, the HCA might have assisted in scaling; I don't think this processes are entirely enabling, particularly for upcoming grass root CLTs'.

Overall, this response suggests that from Lindesfarne's experience, the HCA might have served as an enabler, but the same cannot be entirely said for other start up developers adopting the CLT SEHM model. That is, the HCA's rigorous qualifying procedures sometimes become obstacles to their development ambitions. This posture was buttressed by responses from BU2 who concluded that, there exists a turbulent engagement process between CLTs and a seemingly bureaucratic grip. Regardless, every concerned stakeholder can be considered as a potential enabler. However the need to rightly exploit these potentials to increase CLT performance is undoubtedly crucial as long as the political and institutional willingness is in place.

Recurrent responses that touch on the issue of procurement and bidding complications revolved around the fact that mainstream providers such as the HAs have an overwhelming influence in project allocation. This finding supports Lambert (2011) assertion on the overdependence of the industry on HAs. TD7 on the contrary, feels this is justifiable because of the HA's wellgrounded knowledge base aided by professionals well equipped to manage their portfolios and influence government policies. Recommendations put forward by BU1 on this issue include the need for CLTs to transcend beyond the restricted roles imposed on them due to the effects of competition. BU1 further stated that the: 
'Re-use of dormant properties, [...] earmarked for demolition to fulfil regeneration goals [...] should carve a dominant niche for [CLTs] in affordable housing delivery, to help ward off unfair competition from traditional providers less suited for these roles'.

This position in itself might be contributing to low application of the CLT SEHM on a broader scale. This is because; applicability based on a focus on empty properties by design appears to be residual when juxtaposed with mainstream options. Moreover, these options are often driven by aggressive private, profit and policy interests, perhaps at the detriment of alternative models. Significant responses on the low mainstream recognition of CLTs suggested that the current arrangements seems to limit the CLT SEHM's application to the rural confines; which is underwhelming compared to its potentials on a broader scale. In this regard BU3 suggests that, the [CLT]'s innate attributes should give it a competitive advantage over dominant providers in affordable housing supply. Particularly with properties or communities in areas subject to foreclosures, regeneration initiatives or tenure systems that require flexible and low mortgage plans usually below market rate with affordability guarantee for subsequent homeowners.

\subsection{Institutional conflict in affordable housing project procurement and commissioning}

This section analysed the responses to questions on the possible implications of the overdependence of the UK housing sector on traditional affordable housing providers and models.

\begin{tabular}{|c|c|c|}
\hline Themes/Subthemes & Sources & References \\
\hline Institutional unfair advantage in the affordable housing sector & 14 & 22 \\
\hline 1 'Investor issues' & 4 & 4 \\
\hline 'CLT' 'inadequacies' & 5 & 6 \\
\hline 3 'Clash' of roles among 'providers' & 4 & 7 \\
\hline
\end{tabular}

Table 4: Collation for 'Institutional unfair advantage in the affordable housing sector theme'

In response to the issue of overdependence, both categories of stakeholders affirmed the existence of this problem with clear distinctions in their perspectives. TD5 for example pointed out that this is more of a CLT limitation and investor problem than a case of preferential policy implementation. Hence, the reason the model can be said to thrive mainly in rural communities with huge variations in property prices and average local incomes. For the majority of bottom up respondents, particularly those whose affairs centre on community development, they view this as a situation of unfair advantage that is rampant in the housing industry, particularly against community/cooperative base affordable housing options, with BU1 suggesting that:

'Effecting [...] to ease the processes involved in housing developments, asset management and transfer pathways for properties better suited for community based housing [CLT SEHM] peculiarities'. 
When respondents were asked why this overdependence thrives in the affordable housing sector, there were recurring views among 'top down' respondents centred on the need for a realistic assessment CLT capabilities and scope within the housing industry. TD3 stressed that:

'Status of HA's could be viewed as being a social business and the CLT is [just] a movement [that is] attempting to fill up a role that the HAs and more orthodox social systems already occupy'

BU6 stated:

'[This situation]...restricts the roles/niche of the CLT model to a supplementary one, rather than a fairly competitive [...] based on model merits engaging enough to give room for innovation in affordable housing'.

This assertion supports Deakin (1994); Miles and Huberman (1994); Smyth (1997), that competition is best maximised on a level playing field among competing providers. Therefore it is obligatory for the project implementation processes to take into consideration peculiarities of target localities in the choice of project execution. Therefore, what the CLT lacks in revenue support can be made up with strong research ascertainment centred on its localism ideals among other attributes.

\subsection{Funding capacity and the lack of corporate will to collaborate}

This section analysed responses to the questions on the state of collaboration opportunities with aspiring or start up CLTs and funding difficulties faced.

\begin{tabular}{llll}
\multicolumn{2}{l}{ Themes/Subthemes } & Sources & References \\
\hline \multicolumn{2}{l}{ The lack of corporate will and capacity to collaborate } & 7 & 23 \\
\hline 1 & Dominance of prescriptive policies & 2 & 2 \\
\hline 2 & Weak collaborative platforms & 4 & 4 \\
\hline 3 & Funding problems and the price of conformity & 6 & 14
\end{tabular}

Table 5: Collation of 'the lack of corporate will and capacity to collaborate' theme

Responses from the bottom up categories, asserted that the HAs and LAs play a prescriptive dominant role that might not be efficient enough for housing provision to their local communities, i.e. their conditions for operations are more or less imposed on the community rather than the other way around. Therefore, alternatives with less clout such as the CLT SEHM model suffer. To remedy this situation recurring themes from both categories predictably favoured the continual encouragement of collaboration among stakeholders. TD2 cited cases in which this has worked, however within its agency control:

'[Collaboration]...a major policy introduction, which is fundamental to the grant acquisition process for CLT implementation in respective rural localities'. 
BU4 recommends further collaboration with Community Development Trusts (CDT) involved in affordable housing provision:

'The strengths of [...] CDTs in utilising [assets] community based developments to implement a wide range of local initiatives, are strategic areas the CLTs can exploit to attain more relevance in the scheme of things [housing provision]'

'[...] this would require an arrangement to improve the identification of areas for collaborative opportunities'.

The existing collaborative platforms might help the CLT fulfil certain limited functions, such as providing residual small scale rural housing, but cannot serve as an enabler to maximise the potential for the model's employment in large scale affordable housing provision in both the urban and rural contexts. Despite the fact that there are clear cases of collaborations with the HAs and Local Authorities, they are still very limited, due to unavailability of independent collaboration platforms. Existing ones as suggested by TD2 and BU3 are subjective to prescribed regulations.

Recurrent responses on the issue of funding, clearly points out again that the structural weakness inherent with the CLT model is not conforming with industry lending standards, as TD4 points out:

'There is a limited possibility of the CLT to be taken seriously as an affordable housing option [among lenders] [...] largely its capacity can only be limited to areas that the local authorities and affordable housing stakeholders are yet to occupy'.

Further revelations by TD1, BU3, BU6 and TD7 include the notion that commercial banks hardly see a need to prioritise the funding of CLT SEHM based developments in most of their agenda, with TD7 stating that:

'Maybe a funding source of barrier to CLTs $[\ldots]$ could be more applicable here $[\ldots]$ more of existing structural deficiencies like staircasing restrictions, disadvantage of its attribute which deprives beneficiaries of land ownership [could] limit its acceptability among the mainstream funders, also making it less attractive to potential buyers that might be interested in the model'.

This supposed structural deficiency is further elaborated on by TD3 respondent suggesting that, there is a need for CLTs to increase their flexibility on the issue of 'staircasing (this is a platform that gives legal rights to residents to acquire the free-hold of the land in addition to the housing) restriction' as a key requirement to increase its acceptability among mainstream lenders. TD2 and TD1 elaborated on this situation that:

'At the moment $[\ldots]$ in order to benefit from any fund [from the HCA] 'full staircasing rights' still apply to potential beneficiaries of the housing supplied by its schemes'. 
This situation however goes completely against what makes the CLT unique because if housing beneficiaries are allowed to 'staircase' this would drastically result in the loss of affordability to the open market. BU3 however expressed certain reservations by highlighting that CLTs face the possibility of having to sacrifice its uniqueness in lieu of being taken more seriously by mainstream lenders.

'Getting funding is a major barrier definitely. In the CLT situation; the sales of flats are completely fixed without negotiations [at about $70 \%$ of the open market property rate]'

'[...] the organisation is able to retain $30 \%$ of the flats fixed at perpetuity then retaining the mandate to control the resale price'.

These opinions appear to rule out traditional lenders as reliable sources of finance for housing providers adopting the CLT model because of staircasing restrictions. In addition TD1 and BU5 respondent ruled out the reliance of land gifts and charity grants as sustainable sources for CLT funding. However, recurrent responses raise the need for the recognition of ethical banks as key financial stakeholders for CLTs suggesting that they can accommodate the limitations of the CLT model:

'Plusdane, traidos and charity bank have a greater role to play in all these [...] their mode of operation does cater for $[\ldots]$ limited versatility in CLT operations'.

Based on this premise there is a need to explore operational practices in ethical banks for innovation opportunities that can be adopted by mainstream lenders in the aspect of CLT funding.

\section{Discussion}

Research findings suggest that regulations such as the PQP process despite its rational intentions might be restricting the applicability of competing alternative affordable housing models. Moreover, the role of 'top down' organisations as enablers is debateable due to tedious bureaucratic hurdles encountered by other start up developers adopting the CLT SEHM. There appears to be a limitation on justifiable adoption of best suited housing provision models for affordable housing supply in both urban and rural contexts, regardless of attribute and suitability. The top down perceptions centred on the notion that the structural and implementation limitations are responsible for the CLT SEHM lopsided acceptability when compared to HA models. The supposed lack of level playing ground in the housing sector can be attributed to an unrealistic need to compete for roles the HAs and more orthodox social housing systems already occupy. The fallouts were reflected in findings which suggest low levels of merit in procurement processes, therefore overlooking the positive attributes and value possible with developers, and communities adopting the CLT SEHM as delivery vehicle for affordable housing.

Alternative views were reflected in the general consensus of 'bottom up' respondents who feel that the industry remains oblivious to the reality of the underperformance of the HAs; therefore 
will rather adapt to the status quo despite inherent difficulties, than give tested alternatives a fair chance. This however restricts or limits the roles/niche of the CLT SEHM to a supplementary one, rather than a competitive alternative, regardless of its model merits and well documented potential to champion community driven innovation in affordable housing delivery. Moreover, it was also identified that the creation of an all-encompassing collaboration platform between providers and stakeholders should be encouraged as a means of mitigating the effects of the domination of HAs in housing delivery. On the issue of funding, findings indicated that aspiring developers adopting the CLT SEHM might have to forgo the model's unique attributes like keeping houses affordable in perpetuity, in order to conform to industry standards. That is if mainstream lenders fail to explore innovation opportunities that can cater for affordable housing providers utilising the CLT SEHM model, for example operational practices obtainable in ethical banks.

\section{Conclusion}

This research examined affordable housing problems critically with more vigour from the point of view of alternative community based housing systems with emphasis on the CLT SEHM as a delivery vehicle. Moreover, the paper also presented a case for how postmodern housing perceptions are increasingly unfavourable to renewed/alternative models. Research approaches driving the narrative are mainly based on fundamental and sometimes one sided overviews of stakeholder influence and approach in the housing industry. To this effect, the study found out that the structuration theory's capacity for methodological applications are much criticised and limited undiluted. Furthermore, just combining the theory with a revision of an up to date account of the current state of the SEHM network is not sufficient to uncover reality lost in the quagmire of empiricist data common within the housing discourse. The study therefore proposed the housing pathway framework as a remedy, which focuses on detailed accounts of agents' knowledge, motivation and dialectic control of perception, in order to properly apply the concept of structuration. Maximising the housing pathway cross-sectional wise overtime was seen as a limitation, due in part to constraints of research funding and administration cost which might not support long term research. Due to study scope, this additional process was considered unnecessary. Regardless, the adopted housing pathway gave a representative outlook of the SEHM phenomenon that builds up a reality from both the positivist and interpretivist time frame, i.e. past, present and future (recommendations) perspectives. It also clarified dualistic postulations on the actual impact of 'top down' policies and approach on the alternative housing models, thus identifying barriers and drivers respectively.

After a careful assessment of overall perspectives, implication of industry policy impacts on the CLT SEHM occurred in crucial bilateral dimensions i.e. as a model available for adoption by providers to deliver large scale affordable housing and as a trust in collaboration with local authorities for small scale rural affordable housing provision. Enabling factors and recommendations include the provision of a level playing field to encourage merit in procurement processes and community based innovation in housing delivery. Creation of effective collaborative platforms autonomous enough to regulate the 'top down' grips of CLT dependency on housing associations. This will not occur entirely without a degree of 'top 
down' planning, but should incorporate a 'bottom up' localised approach. On the issue of funding, there is the need to explore the potentials of replicating operational and strategic finance structures existing in ethical banks among mainstream financial institutions. This can help improve CLT representation in the funding network as a viable vehicle for regeneration goals and recession proof affordable housing on a broader scale.

The research has identified the need for expansion of CLT SEHM roles with due recognition of its attributes which can be used as a leverage against unfair competition, hence improving its contribution towards viable affordable housing supply and deficit control in the UK. This improves the state of equal opportunity in procurement, through the consideration of individual model merits as earlier mentioned, without compromising the duties of local authorities, but rather strengthening their strategic housing decision making process. In this light, local authorities should in turn encourage a robust approach to housing delivery, which will not only impact appointment of preferred bidders, but also the right delivery model for their affordable housing endeavours. The potential of alternative models such as the CLT SEHM challenging the status quo might have manifested into institutional sources of barrier, hence stifling fair competition and sufficient room for innovative options in UK housing development.

Despite policy changes veering towards the localism ideal, (which the CLT SEHM epitomises in its attributes) the CLT situation remains at risk of significant redundancy due to its perceived 'non-profit' based shortcomings. This certainly hampers its ability to generate enough interest from investors and the government, particularly in large scale delivery of perpetually affordable housing in both the urban and rural regions. This could explain why its utilisation has been mostly restricted to isolated small scale rural developments in the UK. Without adequate political will, addressing these industry implications might be tantamount to restructuring the CLT SEHM's supposed 'structural shortcomings', which happens to be its distinctive strengths in comparison to traditional models.

\section{References}

Best, R. (2003). Britain's housing in 2022: More shortages and homelessness? York: Joseph Rowntree Foundation/YPS.

Birchall, J. (2004). Cooperatives and the Millennium Development Goals. Geneva: International Labour Office.

Birchall, J. (2004). Cooperatives and the Millennium Development Goals. Geneva: International Labour Office.

Bland, R. (2008). Community Land Trusts, the New Panacea? Delivering Affordable Housing in Rural Areas. London: RTPI.

Bratt, R. (2005). Dilemma of Community Based Housing. Policy Studies Journal, 16(2), 324334. 
Bretherton, J., \& Pleace, N. (2008). Residents' views of new forms of high density affordable living. Coventry: Chartered Institute of Housing.

BSHF. (2016). Community-Led Housing Case Sudies. Coalville: Building and Social Housing Foundation.

BSHF. (2017). Community-led housing: What is it and what can it offer your local authority? Coalville: Building and Social Housing Foundation.

Carnis, H. (2009). The economic theory of bureaucracy: insights from the niskanian model and the misesian approach. Austrian Economics, 12(3), 57-78.

CCMH. (2009). Bringing democracy home. West Bromwich: CCMH.

Clapham, D. (2010). Housing Pathways: A Post Modern Analytical Framework. Housing, Theory and Society, 57-68.

Clapham, D., Means, R., \& Munro, M. (1993). Housing, the life course and older people in Arber S. and M. Evandrou (eds), Ageing, Independence and the Life Course. London: Jessica Kingsley.

Clark, M. (2012). Housing Cooperatives: Are we better together? Retrieved March 13, 2013, from https://www.theguardian.com/housing-network/2012/jan/13/housingcooperatives-affordable-alternatives

CLG. (2011). An introduction to neighbourhood planning. London: CLG.

Community and Local Government. (2008). Community Land Trusts: A Consultation. London: CLG.

Community and Local Government. (2008). Facing the Housing Challenge, Action Today, Innovation Tomorrow. London: CLG.

Community Finance Solutions. (2011). Engaging financial institutions in developing Community Land Trust mortgage. Salford: Community Finance Solutions.

Crang, M. (2002). Qualitative methods: the new orthodoxy? Progress in Human Geography, 26(5), 647-655.

Davis, J. E., \& Jacobus, R. (2008). The City-CLT Partnership: Municipal Support for Community Land Trusts. Cambridge: Lincoln Institute of Land Policy.

Deakin, N. (1994). Evolving relations between government and the third sector in Britain: the case of community care. Conference of International Society for Third Sector Research. Pecs: International Society for Third Sector Research.

Giddens, A. (1984). The constitution of society: Outline of the theory of structuration. Cambridge: Polity Press.

Housing Corporation. (2007). National Affordable Housing Programme 2008-11 Prospectus. London: Housing Corporation.

Inclusionary Housing. (2017). Community Land Trusts. Grounded Solutions Network. 
Jacobus, R. (2015). Inclusionary Housing: Creating and Maintaining Equitable Communities. Cambridge: Lincoln Institute of Land Policy .

Jacobus, R. (2015). Inclusionary Housing: Creating and Maintaining Equitable Communities. Cambridge: Lincoln Institute of Land Policy.

Jacobus, R., \& Abromowitz , D. (2010). A Path to Homeownership: Building a More Sustainable Strategy for Expanding Homeownership. Journal of Affordable Housing, 19(3), 313-344.

Kenny, J. (1992). Housing and Social Theory. London: Routledge.

Kline , P. (1999). The handbook of psychological testing (2nd ed.). London: Routledge.

Lambert, B. (2011). Financing Co-operative \& Mutual Housing. London: CCH.

Latham, M. (1994). Constructing the Team: Final report of the government/industry review of procurement and contractual arrangements in the UK construction industry. London: The Stationery Office .

Leeds, H. W. (2009). Social construction of reality. In S.Littlejohn, \& K.Foss (Eds.), Encyclopedia of communication theory. Thousand Oaks: SAGE Publications.

Mayor of London. (2004). Community Land Trusts \& Mutual Housing Models: A research report for the Mayor of London. London: Greater London Authority.

McNamara, C. (1999). General Guidelines for Conducting Interviews. Minnesota: UM.

Miles, B., \& Huberman, M. (1994). Making Good Sense Drawing and Verifying Conclusions, in Qualitative Data Analysis. NJ: Wiley.

Miles, B., \& Huberman, M. (1994). Qualitative Data Analysis: an Expanded Sourcebook. California: Sage.

National CLT Network. (2017). Project Funding Sources. Retrieved 07 11, 2017, from National CLT Network: http://www.communitylandtrusts.org.uk/step-by-stepguide/finance/funding-sources

National Housing Federation. (2011). Housing Market Analysis. Oxford: NHF.

Ndela, T., \& Du Toit, A. (2000). Corporate culture as a foundation for successful knowledge management. SA Journal of Information Management, 1(4).

ONS. (2009). Code of Practice for National Statistics. London: Crown.

Paterson, B., \& Dayson, K. (2011). Proof of Concept. Salford: Salford University.

Paterson, E., \& Dunn, M. (2009). Perspectives on utilising Community Land Trusts as a vehicle for affordable housing provision. Local Environment, 14(8), 749-764.

Rajagopal. (2015). The Butterfly Effect in Competitive Markets. London: Palgrave Macmillan.

Rees, J., Mullins, D., \& Bovaird, T. (2012). Third sector partnerships for public service delivery: An evidence review. Third Sector Research Centre, Working Paper 60. 
Roschelle, J., \& Teasley, S. (1995). The construction of shared knowledge in collaborative problem solving. Computer Supported Collaborative Learning, 128, 69-97.

Rubin, J., \& Rubin, S. (2005). Qualitative interviewing. London: Sage.

Sarre, P. (2007). Choice and constraint in ethnic minority housing: A Structurationist View. 11(1), 71-86.

Seale, C. (2004). Qualitative research practice. London: Sage.

Searle, J. (1995). The Construction of Social Reality. New York: The Free Press.

Searle, J. (1997). The Constructions of Social Reality. New York: Free Press.

Smyth, J. (1997). Competition as a means of procuring public services: Lessons for the UK from the US experience. International Journal of Public Sector Management, 10(1), 21-46.

Stoker, G. (2011). Was local governance such a good idea? A global comparative perspective. Public Administration, 89(1), 15-31.

Stones, R. (2005). Structuration theory. New York: Palgrave Macmillan.

UK Cohousing Network. (2017, Feb 5). Threshold Centre Dorset. Dorset, England. Retrieved 2017

Urban Research Centre. (2008). Housing Affordability Literature Review and Affordable Housing Program Audit. Sydney: University of Western Sydney.

Vallejo, Nancy, \& Pierre, H. (2004). Governance and Multi-stakeholder Processes. Winnipeg: International Institute for Sustainable Development.

Varady, D. (2012). A Review of the community land trust reader. Journal of the American Planning Association, 216-217.

Voith, R. P., \& Watcher, S. M. (2012). The Affordability Challenge: Inclusionary Housing and Community Land Trusts in a Federal System. Land Policy Conference. Cambridge: Lincoln Institute of Land Policy. 